\title{
From induction to secretion: a complicated route for cellulase production in Trichoderma reesei
}

Su Yan ${ }^{1,2}$, Yan $X u^{1,2}$ and Xiao-Wei Yu ${ }^{1,2^{*}}$

\begin{abstract}
The filamentous fungus Trichoderma reesei has been widely used for cellulase production that has extensive applications in green and sustainable development. Increasing costs and depletion of fossil fuels provoke the demand for hyper-cellulase production in this cellulolytic fungus. To better manipulate T. reesei for enhanced cellulase production and to lower the cost for large-scale fermentation, it is wise to have a comprehensive understanding of the crucial factors and complicated biological network of cellulase production that could provide new perspectives for further exploration and modification. In this review, we summarize recent progress and give an overview of the cellular process of cellulase production in T. reesei, including the carbon source-dependent cellulase induction, complicated transcriptional regulation network, and efficient protein assembly and trafficking. Among that, the key factors involved in cellulase production were emphasized, shedding light on potential perspectives for further engineering.
\end{abstract}

Keywords: Trichoderma reesei, Cellulase, $\beta$-Glucosidase, Transporter, Induction, Transcription factor, Environmental factor, Secretion

\section{Introduction}

The cellulolytic fungus Trichoderma reesei is one of the most widely applied microorganisms for cellulase production. Approximate $100 \mathrm{~g} / \mathrm{L}$ extracellular cellulase could be produced in T. reesei (Cherry and Fidantsef 2003). The secreted cellulase mainly consists of two major cellobiohydrolases CBHI/CEL7A and CBHII/ CEL6A, endoglucanases EGI/CEL7B and EGII/CEL5A, and $\beta$-glucosidases BGLI/CEL3A which account for $90 \%$ extracellular protein (de Paula et al. 2018). Besides, the hemicellulase, LPMOs (lytic polysaccharide monooxygenases), CIP (cellulose-induced protein) and swollenin which belong to the secretome of $T$. reesei could also participate in the efficient degradation of biomass (Gupta et al. 2016). Such a brilliant cellulase-producing ability is

\footnotetext{
*Correspondence: yuxw@jiangnan.edu.cn

${ }^{1}$ Lab of Brewing Microbiology and Applied Enzymology, School of Biotechnology, Jiangnan University, Wuxi 214122, People's Republic of China

Full list of author information is available at the end of the article
}

increasingly attractive due to the rapid depletion of fossil fuels and the demand for sustainable development. Traditionally, the bioconversion of biomass which needs a large amount of cellulase is costly. Thus, it is critical to reducing the cost of biodegradation by improving cellulase output. T. reesei possesses excellent cellulase production ability, but it only harbors the minimum number of cellulase encoding genes among other fungi (Martinez et al. 2008). The specific regulators and unique cellulase response mechanism may give $T$. reesei superb cellulase production ability and greater potency in a saprotrophic habitat.

Great effort has already been made to identify the crucial factors involved in the cellulase production in T. reesei. Recently, numerous studies for deeper understanding and genetic engineering of cellulase production in $T$. reesei were conducted, including the identification of new regulators, characterization of the key signal transduction pathways and the discovery of the special factors that function in cellulose sensing (Chen et al. 2016; 
Karimi Aghcheh et al. 2014; Xu et al. 2014; Zhang et al. 2019; Zou et al. 2018). The mechanisms and critical factors in cellulase production were gradually uncovered in this genetic era.

To better engineer $T$. reesei for cellulase production, it is wise to have a comprehensive understanding of the crucial factors and complicated biological network of cellulase production that could provide new perspectives for rational modifications. Previous reviews have mainly focused either on metabolic analysis (Kubicek et al. 2009), transcriptional regulation (Druzhinina and Kubicek 2017) or secreting pathways (Saloheimo and Pakula 2012; Wang et al. 2020) for rational improvement of cellulase production. However, cellulase production in T. reesei is a complicated process, and the relevant pathways are simultaneously regulated through multiple factors that have not been fully elucidated. In this article, based on current studies, the cellular process of cellulase production in $T$. reesei, consisting of carbon source-dependent cellulase induction, complicated transcriptional regulation network, and efficient protein assembly and trafficking, are broadly reviewed, giving new perspectives for further exploration and engineering.

\section{Carbon source-dependent cellulase induction Cellulase production is induced by cellulose and its oligosaccharides}

Cellulase production is efficiently induced using cellulose as the carbon source in $T$. reesei. However, insoluble cellulose could never be taken in and participated in the cell metabolism. Besides, cellobiose was verified for partly cellulase induction in T. reesei (Mandels and Reese 1960), drawing speculation that the released cellobiose from lignocellulose induces cellulase production. Moreover, the basal transcription of CEL5B and the conidial-bound cellulases (mainly CEL6A) are also involved in induction initiation (Fig. 1), which has been reviewed by (Kubicek et al. 2009). Furthermore, the sophorose, which is transglycosylated from cellobiose by $\beta$-glucosidases, could

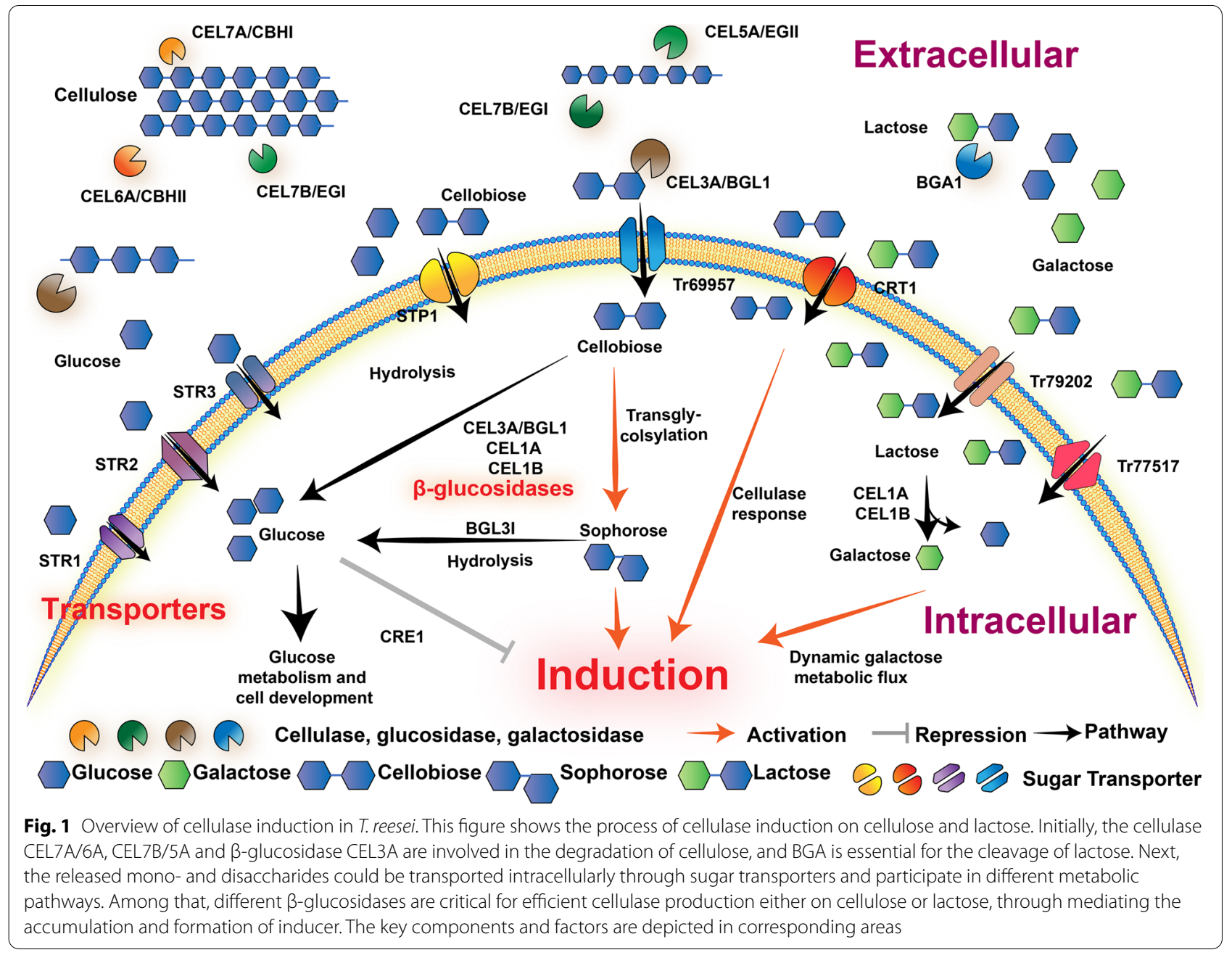


significantly trigger cellulase induction, shedding light on the critical role of $\beta$-glucosidases in cellulase induction.

In $T$. reese $i, 11 \beta$-glucosidases were annotated which belong to the GH1 and GH3 family (Hakkinen et al. 2012), functioning in oligosaccharides hydrolysis. Besides, fungal $\beta$-glucosidase is also a transferase, which could form $\beta$-linked disaccharides with the presence of glucose and cellobiose (Sternberg and Mandels 1979). Indeed, sugar transglycosylation is important for cellulose-based cellulase induction, which could form inducer and trigger efficient inducing cascade. BGL1/ CEL3A is the most abundant extracellular $\beta$-glucosidases that participate in cellulase induction. The bgl1 null mutant showed delayed cellulase induction. However, the induction defect could be restored with the addition of sophorose, indicating the significant role of transglycosylation by $\beta$-glucosidase (Fowler and Brown 1992). However, Mach et al. (1995) showed a different result, that a bgl1-deleted mutant showed less cellulase induction using sophorose as the sole carbon source. Further work in which all $\beta$-glucosidase activities were blocked through the addition of $\beta$-glucosidase inhibitor nojirimycin totally impaired the cellulase induction on sophorose, suggesting that the $\beta$-glucosidase might also exert an unknown function on cellulase induction through forming another inducing component (Mach et al. 1995). These results suggest a more complex process to elucidate. Meanwhile, intracellular $\beta$-glucosidases also play a significant role in cellulase induction through balancing the hydrolysis and transglycosylation activity. The deletion of cella resulted in decreased cellulase induction using either Avicel or cellobiose as a carbon source but not using sophorose, which might be attributed to decreased intracellular transglycosylation (Shida et al. 2015; Zhou et al. 2012). Moreover, a single-nucleotide mutation of V409F influencing substrate binding in CEL1A compromised the intracellular $\beta$-glucosidase hydrolysis activity. The delayed cleavage and consumption of cellobiose, intracellularly, results in a higher accumulation of sophorose that would further increase the cellulase induction on Avicel and cellobiose (Shida et al. 2015). In addition, the appropriate amount of cellobiose was shown to be essential for efficient cellulase induction, that the cellobiose addition could rescue the induction defect on Avicel in the glucosidase null mutants (Zhou et al. 2012). Besides, $\beta$-glucosidase BGL3I was also reported to induce cellulase through mediating sophorose cleavage (Zou et al. 2018). In addition, $\beta$-glucosidase CEL3D might also be involved in cellulase induction, although the mechanism needs further investigation ( $\mathrm{Li}$ et al. 2016). Recently, the $\beta$-glucosidases were comprehensively investigated for their cellular distribution and function in cellulase induction (Pang et al. 2021). Different $\beta$-glucosidases were shown to harbor varied localizations, which might engage in different cellular processes for cellulase induction. And the multi-copy of glucosidase resulted in comparable or decreased cellulase production compared to the parent strain (Pang et al. 2021), which might be attributed to increased disaccharides hydrolysis.

In brief, cellulase induction on cellulose in $T$. reesei is a complicated process that is coordinated by different factors, such as the saccharides concentration, specific activity of cellobiose hydrolysis and transfer, different roles of $\beta$-glucosidases in cellulase induction, etc. (Fig. 1). Significantly, the 11 different $\beta$-glucosidases could serve as critical factors in cellulase induction. Except for three well-characterized $\beta$-glucosidases, CEL3A, CEL1A and CEL1B, other $\beta$-glucosidases which show different catalytic properties (Guo et al. 2016) are also critical for efficient cellulase induction. Further study would focus on those poorly investigated glucosidases which might unravel the regulating mechanism of cellulase induction.

\section{Cellulase induction on lactose}

In addition to cellulose and its oligosaccharide derivatives, the heterodisaccharide lactose has also been reported to induce cellulase production at a moderate level (Bischof et al. 2016). Lactose is a byproduct of the food industry and is present at very low concentrations, if at all, in the habitat of $T$. reese $i$, which prefers a saprotrophic lifestyle. Compared to cellulose, soluble and economically friendly lactose is more suitable for industrial cellulase fermentation ( $\mathrm{Li}$ et al. 2017; Liu and Qu 2019). Hence, the mechanism of lactose induction seems to be preferably explored and engineered for further improvement of cellulase induction on lactose.

The utilization of lactose is initiated from the cleavage of the lactose into glucose and galactose, which is mainly conducted by extracellular $\beta$-galactosidase BGA1 or intracellular $\beta$-glucosidases CEL1A and CEL1B, which harbor $\beta$-galactosidase activities (Seiboth et al. 2005; $\mathrm{Xu}$ et al. 2014). Besides, two intracellular CEL1A and CEL1B are critical for cellulase induction on lactose due to the $\Delta b g a 1$ strain showed a lower growth rate on lactose but no change in cellulase induction (Seiboth et al. 2005) (Fig. 1). In contrast, the elimination of intracellu$\operatorname{lar} \beta$-galactosidase activity through the deletion of cella and cel1b totally impaired cellulase production on lactose (Xu et al. 2014). $\beta$-Glucosidase BGL3I has also been described to increase the transcription level of cellulase genes on lactose, mainly through indirectly controlling extracellular lactose hydrolysis and lactose transport (Zou et al. 2018).

After cleavage, the released glucose serves as a repressor of cellulase induction due to CRE1-mediated CCR (carbon catabolite repression), and galactose might play 
a crucial role in cellulase induction (Karaffa et al. 2006). The utilization of galactose usually requires the cooperation of multiple enzymes in different metabolic pathways, including the Leloir pathway and alternative D-galactose pathway, which was illustrated by Kubicek et al. (2009). It was assumed that the metabolic rate and flux of galactose and the formation of intermediate metabolite would influence the cellulase induction. Karaffa et al. (2013) also reported a correlation between inner galacto-oligosaccharides and cellulase production, suggesting that the inducer was produced through metabolism. Moreover, the galactose addition could also rescue the cellulase induction defect in $\Delta$ cel1a mutant on lactose medium, although it was independent of the galactose metabolism (Seiboth et al. 2007).

The cellulase induction on lactose is an intricate process, which was well-coordinated by the intracellular glucosidases and galactose metabolic flux (Fig. 1). Similar to the pattern of cellobiose in cellulose-based induction, the hydrolysis of lactose and the accumulation of galactose both give an indispensable role in cellulase induction. Meanwhile, lactose metabolism shares a tight connection with transcriptional factors, such as XYR1 and ACE3 (Stricker et al. 2007; Zhang et al. 2019), indicating a dynamic regulation by transcription factors and metabolism networks. Furthermore, the indispensable of $\beta$-glucosidase CEL1A in cellulase induction on lactose (Xu et al. 2014) raises the possibility of other unraveled functions of glucosidase in cellulase induction, such as the formation of other potency inducers which could efficiently trigger inducing cascades. Based on the result till now, it is still elusive to draw a conclusion of the clear mechanism of cellulase induction on lactose. However, the critical factors are gradually investigated, which gives a clue for further research, and it values a lot to engineer cellulase production on lactose which would significantly lower the cost for cellulase production.

\section{Sugar transporters are engaged in cellulase induction}

In cellulolytic fungus $T$. reesei, sugar transporters are essential for the perception of cellulose and the uptake of soluble disaccharides, which is critical for efficient cellulase induction (Nogueira et al. 2020). In T. reesei, only a few disaccharide transporters have been characterized. For example, the cellobiose transporter STP1 is also capable of glucose transport, and the absence of stp1 resulted in increased cellulase induction on cellulose, which is attributed to decreased glucose input (Zhang et al. 2013). Meanwhile, another disaccharide transporter CRT1 was verified for lactose and cellobiose transport (Havukainen et al. 2020; Porciuncula et al. 2013), importantly, CRT1 is also critical for efficient signal cascade transmission that the absence of CRT1 resulted in totally impaired cellulase induction (Zhang et al. 2013). Besides, Tr79202 and Tr77517 are also capable of lactose transport, and the cellulase induction on lactose is compromised in its deletion mutant (Porciuncula et al. 2013). Moreover, the transporter Tr69957 which is involved in cellobiose, mannose and xylose transport participates in the regulation of a few cellulolytic genes in the presence of sugarcane bagasse (Nogueira et al. 2018).

Except for characterized disaccharide transporters, some monosaccharide transporters also participate in the efficient cellulase induction. For example, the xylose transporter STR1 which is capable of glucose transport was upregulated in the presence of straw (Ries et al. 2013). Besides, other characterized xylose (glucose) transporters STR2 and STR3 (Sloothaak et al. 2016) were also highly transcribed in a hyper-cellulase mutant in our study (our unpublished data). Moreover, the highly upregulated transporters in a tubulin-disrupted $(\Delta t u b B)$ strain are also critical for increased cellulase production probably via varied cellobiose uptake (Shibata et al. 2021). And the genes related to transmembrane transport were enriched in our study (data not shown), indicating the important role of sugar transporter which still needs exploration. In addition, the induction and function of transporters are also under the subtle regulation of the endogenous regulation system. About 10 sugar transporters were shown to be probably regulated through two well-characterized transcriptional factors XYR1 and CRE1 (de Paula et al. 2018), which represent the induction pattern on cellulose and repression pattern on glucose, respectively. As shown above, the sugar transporters are suggested to be involved in the efficient cellulase induction through controlling sugar uptake flux which directly affects the accumulation of inducer for downstream inducing cascade. Moreover, the inevitable role of transporter CRT1 in cellulase induction along with other signal transduction pathways discussed in the next chapter also gives the possibility that other unraveled transporters also share such critical roles in cellulase induction, which need further investigation. Meanwhile, the regulation through transcriptional factors indicates that the inducing signal is also under the feedback regulation by inner inducing signals, the activated transcriptional factors by inducing signal might further induce the expression of transporters and control the sugar uptake. Thus, although great effort has been made in fungal sugar transporter, this field is still poorly explored, which represents a potential for genetic engineering (Nogueira et al. 2020).

\section{Cellulase induction is regulated at the transcription level}

Transcriptional regulation is critical for cellulase induction in $T$. reesei, which is mainly manipulated by transcription factors (TFs). Approximate 700 transcription 
factors were annotated in the genome of $T$. reesei (Martinez et al. 2008), while only a few of them has been investigated yet. Besides, other factors such as inner and environmental factors are also involved in transcriptional regulation, which builds a coordinated network for finetuned cellulase production (Fig. 2).

\section{Characterized transcription factors involved in cellulase induction}

Cellulase genes are induced on cellulose via the transcriptional activation by the master regulator XYR1, which controls the expression of a majority of CAZymes genes (Dos Santos Castro et al. 2016). When glucose is present, cellulase induction is repressed through CRE1-mediated CCR (carbon catabolite repression), which is broadly functioned in eukaryotes (de Assis et al. 2021; Portnoy et al. 2011a). Besides, other characterized transcription factors, such as ACE2, ACE3, BglR, etc., involved in efficient cellulase production have already been investigated and reviewed previously (de Paula et al. 2018; Druzhinina and Kubicek 2017; Gupta et al. 2016), and the key information is briefly listed in Table 1.
Moreover, in the past 5 years, many new TFs were characterized, and their regulatory mechanisms were gradually uncovered (Table 1). CLR1 and CLR2 in T. reesei have been identified as the homologs of CLR1 and CLR2 in Neurospora crassa (Coradetti et al. 2012). These genes are crucial for cellulase induction in N. crassa, but in T. reesei, CLR1 and CLR2 have a minor effect on cellulase and instead are mainly responsible for xylanase regulation upstream of XYR1 and XPP1 in response to light (Beier et al. 2020a). Similarly, RXE1 was identified as an activator of XYR1 through direct binding to the $x y r 1$ promoter (Wang et al. 2019a), together with CRE1 modulating the cellulase induction on different carbon sources. The $\mathrm{C}_{2} \mathrm{H}_{2}$ zinc finger TF AZF1 in T. reesei has been reported to directly bind to the promoters of $c e l 7 a, c e l 45 a$ and swo 1 and positively regulate their transcription on Avicel (Antonieto et al. 2019). Moreover, the plant homeo domain (PHD) protein CLP1 could also activate cellulase transcription with XYR1 at the promoter of cel7a and cel7b (Wang et al. 2019b), although the precise mechanism needs further investigation. Recently, it was found that a cellulase regulator RCE1 specifically served as a repressor for cellulase induction

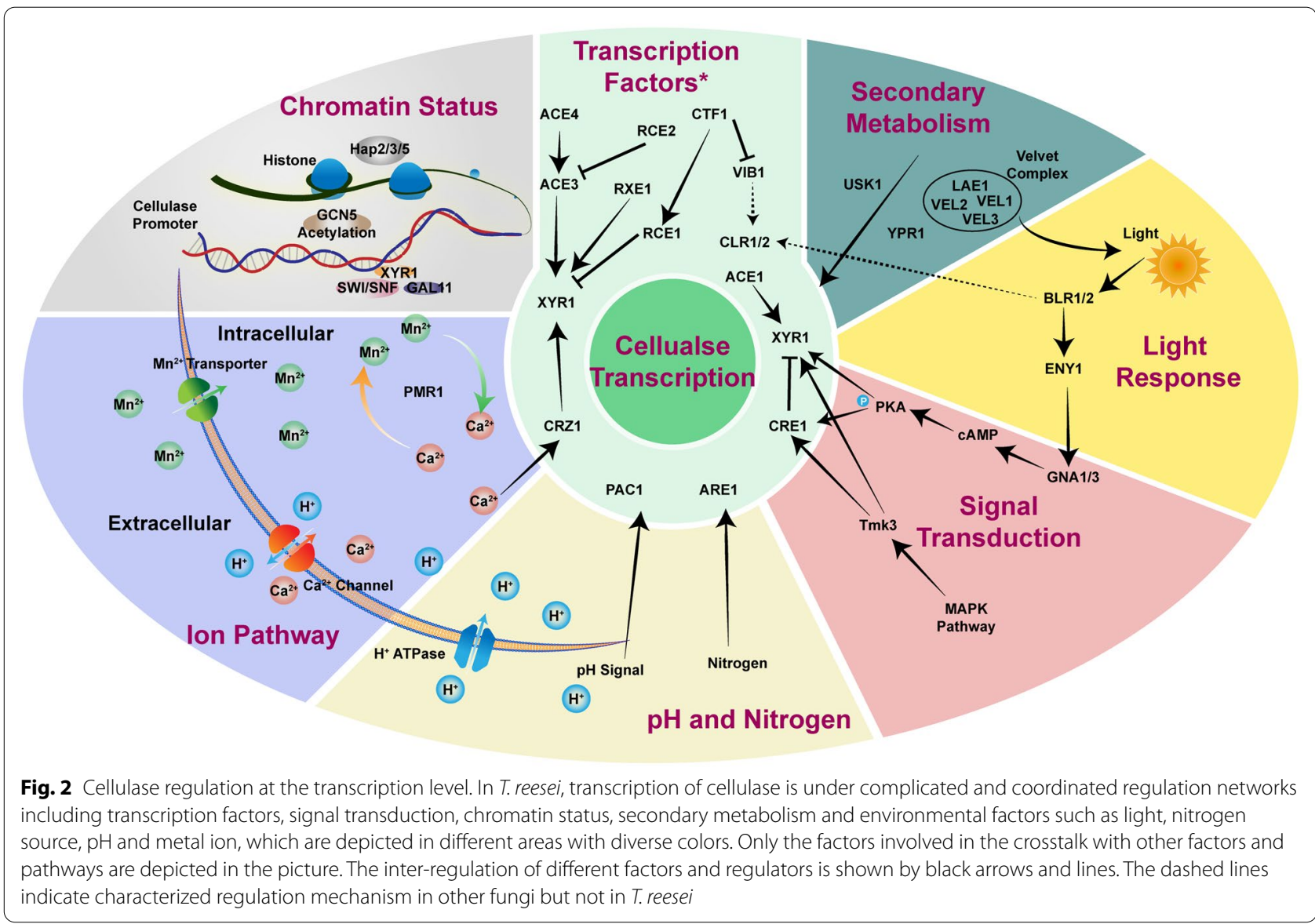


Table 1 Transcription factors involved in cellulase regulation in T. reesei

\begin{tabular}{|c|c|c|c|}
\hline TFs & Downstream genes & Binding sequences & Reference \\
\hline \multicolumn{4}{|l|}{ Activator } \\
\hline XYR1 & Majority of cellulases & $\mathrm{GGC}(\mathrm{A} / \mathrm{T})_{3}$ & (Kiesenhofer et al. 2018) \\
\hline ACE2 & Majority of cellulases & GGCTAATAA & (Portnoy et al. 2011b) \\
\hline ACE3 & Majority of cellulases & $\operatorname{CGGAN}(\mathrm{T} / \mathrm{A})_{3}$ & (Zhang et al. 2019) \\
\hline ACE4 & cel7a, ace3, cel6a, xyr1 & Two adjacent -GGCC- & (Chen et al. 2021 b) \\
\hline$B g \mid R$ & $\beta$-Glucosidases (except for cel3a) & $-{ }^{\mathrm{a}}$ & (Nitta et al. 2012) \\
\hline CLR1/2 & Xylanase, cellulase, xyr1, xpp 1 & - & (Beier et al. 2020a) \\
\hline RXE1 & xyr1 & - & (Wang et al. 2019a) \\
\hline AZF1 & cel7a, cel45a, swo 1 & - & (Antonieto et al. 2019) \\
\hline CLP1 & cel7a, cel7b & - & (Wang et al. 2019b) \\
\hline PAC1 & Cellulase, xylanase & GCCARG $^{b}$ & (Hakkinen et al. 2015; He et al. 2014) \\
\hline CRZ1 & xyrl,cel7a & $(\mathrm{T} / \mathrm{G}) \mathrm{GGCG}$ or GGGC(G/T) & (Chen et al. 2016) \\
\hline ARE1 & cel7a, cel6a, cel7b, cel5a & HGATAR & (Qian et al. 2019) \\
\hline VIB1 & Cellulase & - & (Ivanova et al. 2017; Zhang et al. 2018a) \\
\hline \multicolumn{4}{|l|}{ Repressor } \\
\hline CRE1 & Majority of cellulases, xyr1 & SYGGRG & (Portnoy et al. 2011a) \\
\hline ACE1 & Majority of cellulases, xyr1 & AGGCA & (Saloheimo et al. 2000) \\
\hline RCE1 & cel7a, cel7b, cel3a & $\mathrm{GGC}(\mathrm{A} / \mathrm{T})_{3}$ & (Cao et al. 2017) \\
\hline RCE2 & Majority of cellulases, xyr1, cre 1 and ace 3 & (T/A)NNNNCCG and CGGNNNN(T/A) & (Chen et al. 2021c) \\
\hline CTF1 & vib1, rcel, ace3 & - & (Meng et al. 2020) \\
\hline $\mathrm{YPR}^{\mathrm{c}}$ & Cellulase and SOR clusters & - & (Derntl et al. 2016; Zhang et al. 2021) \\
\hline
\end{tabular}

through directly bound to the cel7a promoter, competing with XYR1 for the same recognition site (Cao et al. 2017). In addition, a repressor CTF1 was isolated via an artificial zinc finger library, and the deletion of $c t f 1$ caused a global increase in cellulase gene expression (Meng et al. 2020). Another activator ACE4 was also shown to participate in the cellulase induction mainly through regulating the expression of ACE3 (Chen et al. 2021b). Recently, the biological function of a novel repressor RCE2 was characterized to repress expression of a majority of cellulase genes, and transcription factors such as cre $1, x y r 1$ and ace3. A binding competition between RCE2 and ACE3 was also observed, indicating a synergetic regulation among RCE2 and other transcription factors (Chen et al. 2021c).

\section{Other factors involved in transcriptional regulation}

Aside from these specific transcription factors, other factors involved in secondary metabolism, signal transduction and chromatin status regulation also participate in the transcriptional modification of cellulase production in different aspects (Fig. 2).

\section{Secondary metabolism}

The velvet protein complex, which consists of LaeA, VeA, VelB and VelC in Aspergillus nidulans, is conserved in fungi and regulates secondary metabolism and photodependent development (Bayram and Braus 2012). The homolog of LaeA in $T$. reesei is annotated as LAE1 and controls the activation of XYR1 on cellulase induction. The transcription of $x y r 1$ was impaired in the lae 1 null mutant, and the constitutively expressed XYR1 could not rescue the induction defect in $\Delta l a e 1$, indicating that LAE1 is an upstream regulator of XYR1 (Seiboth et al. 2012). VEL1 is the homolog of VeA in A. nidulans and shows a function similar to that of LAE1 upon cellulase induction in T. reesei (Karimi Aghcheh et al. 2014). Further function investigation through vel1, vel2 or vel3 deletion also verified their critical role in secondary metabolism due to reduced sporulation, as well as the diminished cellulase expression especially in $\Delta v e l 1$ and $\Delta v e l 2$, indicating a more significant role of VEL1 and VEL2 in this regulon (Liu et al. 2016). These results all demonstrate the significant role of the velvet protein complex in cellulase induction as well as secondary metabolism regulation. Besides, the overexpression of the transcription factor YPR1, which is involved in polyketide synthase (PKS)-encoding genes regulation, dramatically increased sorbicillin production, but the cellulase production was decreased mainly through unbalanced regulation between cellulase production and secondary 
metabolism (Zhang et al. 2021). And the protein kinase USK1 in the vicinity of sorbicillin producing genes could also regulate secondary metabolism and cellulase production in darkness (Beier et al. 2020b).

\section{Signal transduction}

Transcription factor VIB1 in T. reesei was also investigated because of a distal chromosome translocation in a cellulase-negative mutant QM9978, which causes a loss of function of VIB1 (Ivanova et al. 2017). The overexpression of VIB1 enhanced cellulase production but with lower biomass accumulation (Zhang et al. 2018a). VIB1 in $N$. crassa controls many pathways, including carbon signal transduction and CCR, and it could also regulate cellulase expression through modulating CLR2 (Zhang et al. 2018a); thus, in T. reesei, the function of VIB1 and how VIB1 could regulate cellulase production needs further investigation. The mitogen-activated protein kinase (MAPK) pathway, which is ubiquitous in eukaryotes and is involved in biological regulation, could also participate in the regulation of cellulase expression through the phosphorylation of transcription factors by TMK3 in T. reesei (Wang et al. 2013). Although the deletion of another transcription factor TMK1 in MAPK pathway could increase cellulase production, it is independent of the transcriptional regulation of cellulase expression (Wang et al. 2017). Moreover, the cellulase inducing signal received through heterotrimeric $G$ proteins receptors activates the $\mathrm{G} \alpha$ subunit, mostly GNA1/3 (responsible for cellulase induction)(Schmoll et al. 2009; Seibel et al. 2009), and elevates downstream cAMP abundance. The main target of cAMP in this cascade is protein kinase A (PKA), which could phosphorylates other transcription factors, such as the main repressor CRE1 in CCR (Cziferszky et al. 2002), and other upstream factors regulating xyr1 expression (Schuster et al. 2012). The CRE1 phosphorylation is crucial for its repression function that a E244V mutation which leads to dephosphorylation and loss of DNA binding ability (Cziferszky et al. 2002). A subtle exchange of C-terminal phosphorylation site S388 to valine resulted in an unphosphorylated state, which improved cellulase production regardless of CCR in the presence of glucose (Han et al. 2020a, b). This data collectively suggested an inevitable function of phosphorylation of normal regulation of transcription factor, which serves as promising candidate for engineering.

\section{Chromatin status}

In eukaryotes, DNA is wrapped around histones to form the nucleosome; the transcription and activation of genes sometimes require the release of histones and trigger nucleosome repositioning. The HAP2/3/5 complex, which is widely conserved in eukaryotes, could also participate in chromatin remodeling. The transcriptional activation of $c b h 2 /$ cel6a in $T$. reesei has been reported as the result of the depletion of nucleosome occupancy downstream of CAE (cbh2-activating element) under induction conditions (Zeilinger et al. 2003). The negative regulator CRE1 was also noted for its significant role in nucleosome positioning under repression conditions, combined with the upregulation of SWI/SNF complex (Ries et al. 2014). Further work on XYR1 also demonstrated that XYR1 is indispensable for chromatin remodeling and transcription activation under cellulose induction through binding to TrSNF12 and TrGAL11 at its acidic activating domain (Cao et al. 2019; Zheng et al. 2020a). Moreover, transcription activation also requires GCN5-mediated histone acetylation, which affects chromatin status (Xin et al. 2013).

\section{Transcriptional regulation via environmental factors}

It is essential for microorganisms to sense environmental factors, such as light, nitrogen, $\mathrm{pH}$ and metal ions, to maintain homeostasis and biorhythms. Cellulase production in T. reesei is also under the regulation of several environmental factors at the transcription level (Fig. 2).

\section{Light}

Light is a significant signal that can regulate cell metabolism and rhythm. In T. reesei, ENY1 has been reported as a regulatory protein that influences cellulase expression in response to light (Schmoll et al. 2005). Further study has identified two photoreceptors, BLR-1 and BLR-2, the homologs of Wc-1 and Wc-2 in N. crassa, which can sense light and activate the transcription of eny1 (Castellanos et al. 2010). Then, the downstream G-protein $\alpha$ subunits GNA- 1 and GNA-3 are activated and affect the downstream cAMP and PKA (protein kinase) pathway, indicating crosstalk between light sensing and signal transduction (Schmoll et al. 2009; Seibel et al. 2009; Tisch et al. 2014). Additionally, the study of cAMP in response to light showed that deletion of adenylate cyclase acyl and cAMP-dependent protein kinase A pkac1 disturbs the cellulase regulation in response to light (Schuster et al. 2012), indicating the significance of light regulation for cellulase expression via the cAMP pathway. Besides, the phospholipase $\mathrm{C}$ plc-e was verified for its vital role in inducing signal cascade between cAMP and downstream $\mathrm{Ca}^{2+}$ signaling pathway (Chen et al. 2021a), which is depicted in detail below. Besides, the light response cellulase production was also regulated via velvet protein complex, that the decreased cellulase expression was only shown in dark, but almost unchanged in light condition in $\Delta v e l 3$ T. reesei (Liu et al. 2016). Meanwhile, the light receptor white-collar complex (WCC) has also been reported to directly bind to the promoter of $c l r-1$ in $N$. 
crassa (Smith et al. 2010), which suggests a direct regulation by light. And a positive regulation by ENY1 on major cellulase activator such as XYR1 and ACE3 also give a indispensable role of light regulation among transcription factors (Schmoll 2018).

\section{Nitrogen sources}

In addition, different nitrogen sources could also influence cellulase production. ARE1 is responsible for protease production through direct regulation of apw1 and apw2 in T. reesei. Further study confirmed that it could also regulate the transcription of cel7a and cel6a when cultured with $\left(\mathrm{NH}_{4}\right)_{2} \mathrm{SO}_{4}$ as nitrogen source (Qian et al. 2019), which demonstrates crosstalk between cellulase production and nitrogen metabolism.

\section{pH}

Environmental pH can influence the basal metabolism of fungi (Li et al. 2013), and it can also affect cellulase production. A transcription factor PAC1 in T. reesei has been characterized as a homolog of PacC in A. nidulans, and it can receive $\mathrm{pH}$ signals through the pal pathway and regulate cellulase production in neutral $\mathrm{pH}$ (He et al. 2014). Although several cellulase genes are pH-responsive, relatively few cellulase genes are under PAC1 regulation (Hakkinen et al. 2015), suggesting the presence of an alternative regulator that could influence cellulase transcription with different $\mathrm{pH}$ signals. Moreover, PacC in A. nidulans was shown to directly bind to the GGCARG motif for its regulatory activity (Espeso et al. 1997), while the detailed function of PAC1 in $T$. reesei has not yet been investigated. In addition, the balance of intracellular and extracellular $\mathrm{pH}$ is maintained by $\mathrm{H}^{+}$-ATPase (Liu et al. 2019b). The acidic metabolites produced during cell development would lower the intracellular $\mathrm{pH}$, thus, proton exchange via different pumps is indispensable for $\mathrm{pH}$ homeostasis. In T. reesei, the $\mathrm{H}^{+}$-ATPase $\operatorname{Tr} 76238$ could efficiently output $\mathrm{H}^{+}$. Deletion of the $\mathrm{H}^{+}$-ATPase would increase the intracellular $\mathrm{H}^{+}$concentration and stimulate $\mathrm{Ca}^{2+}$ input through $\mathrm{Ca}^{2+}$ channels, which then would increase cellulase transcription through the $\mathrm{Ca}^{2+}$ signal transduction pathway (Chen et al. 2016).

\section{Metalions}

The $\mathrm{Ca}^{2+}$ signal transduction pathway in eukaryotes has been widely reported to be involved in diverse biological processes, including cell development and environmental stress responses (Hagiwara et al. 2008). Mandels and Reese first reported that the addition of $2.5 \mathrm{mM} \mathrm{Ca}^{2+}$ increased cellulase production in T. reesei (Mandels and Reese, 1957), and Chen et al. uncovered the calcineurindependent $\mathrm{Ca}^{2+}$ signal transduction pathway and identified the regulator CRZ1 (calcineurin-responsive zinc finger transcription factor 1) (Chen et al. 2016), which is involved in regulating $x y r 1$ and cel7a transcription. The addition of $\mathrm{Mn}^{2+}$ was also suggested to increase cellulase production in $T$. reesei by triggering the $\mathrm{Ca}^{2+}$ signal pathway (Chen et al. 2018). Two $\mathrm{Mn}^{2+}$ transporters, TPHO84-1 and TPHO84-2, were also identified, whose deletion showed lower cellulase production compared to that with $\mathrm{Mn}^{2+}$ addition. Besides, the $\mathrm{Ca}^{2+} / \mathrm{Mn}^{2+}$ homeostasis is maintained through the $\mathrm{Ca}^{2+} / \mathrm{Mn}^{2+}$ transporter PMR1, the deletion of which became less sensitive to extracellular $\mathrm{Mn}^{2+}$ addition (Chen et al. 2018). The reason for this might be explained by the disordering of $\mathrm{Ca}^{2+}$ / $\mathrm{Mn}^{2+}$ balance and the blocking of CRZ1-mediated transcriptional activation. The $\mathrm{Ca}^{2+}$ signal transduction pathway seems to be the dominant ion transduction pathway in $T$. reesei that could engage in crosstalk with other pathways and influence cellulase production (Fig. 2). Although the $\mathrm{Ca}^{2+}$ signal transduction pathway and its interaction with the $\mathrm{Mn}^{2+}$ pathway were also observed in $A$. nidulans (Hernández-Ortiz and Espeso 2013), the function of the regulator CrzA has been reported in response to cellular stress and $\mathrm{Ca}^{2+}$ homeostasis in $A$. nidulans, but not yet for others. Recently, the traditionally used solvent $\mathrm{N}, \mathrm{N}$-dimethylformamide (DMF) has been reported for enhancing cellulase production through changing cell plasma membrane permeability (Chen et al. 2019), which then creates an intracellular $\mathrm{Ca}^{2+}$ burst and activates downstream $\mathrm{Ca}^{2+}$ signal transduction. However, other organic solvents, such as DMSO, did not have a similar effect. In T. reesei, the interactive work between $\mathrm{Mn}^{2+}$ and $\mathrm{Ca}^{2+}$ signal pathway, signifying the importance of $\mathrm{Ca}^{2+}$ in the cellulase induction, provides a new perspective on whether other metal ions might also be involved in the signaling pathway, which in turn had a positive effect on cellulase induction.

As shown above, cellulase induction is a well-coordinated process and could be influenced by different factors which finally affect cellulase induction at the transcription level via multiple transcription factors. The discovery of novel transcription factors and clarification their mechanism mean a lot for rational engineering (Sun et al. 2020; Yan et al. 2021) and partly give a clue for understanding the regulation network upon cellulase induction. However, the characterized transcription factors only account for a small percentage of all the annotated transcription factors in T. reesei, which is still a promising area for further investigation.

\section{The brilliant secreting ability for cellulase production}

Same as other eukaryote microorganisms, T. reesei can also systematically process secreted protein through folding and proper decoration. As the desired platform for 
cellulase production, exceed $100 \mathrm{~g} / \mathrm{L}$ cellulase could be secreted in Trichoderma species (Cherry and Fidantsef 2003), drawing strong focus on how could this species secretes such a huge amount of cellulase. Traditionally, the protein secretion underwent the classical secretion pathway including translation in the ribosome, folding in the endoplasmic reticulum (ER), glycosylation in Golgi and finally transported extracellularly. A detailed review of this classical secretion pathway in yeast and other fungi has already been investigated and could be found elsewhere (Celinska and Nicaud 2019; Shoji et al. 2008). In this section, the characterized secretion factors in $T$. reesei involved in efficient cellulase production are reviewed. Meanwhile, the critical pathways characterized in other fungi are also emphasized, which shed light on further investigation in T. reesei (Fig. 3).

\section{Efficient protein assembly and quality control in ER}

The cellulase secretion is initiated from the protein translation in the ribosome, then followed by the intricate assembly in the endoplasmic reticulum (ER). The polypeptides entering into the ER lumen need to be folded with the assistance of binding protein $\mathrm{BiP} 1$ and protein disulfide isomerase PDI1. BiP1 is the homolog of Kar2 in $S$. cerevisiae, which belongs to the HSP 70 family, functioning in the folding of proteins in the ER. PDI1 is involved in the formation of disulfide bonds with pdi1 oxidase ERO1 (Conesa et al. 2001). Moreover, the preliminary glycosylation is also conducted in ER via the oligosaccharyltransferase OST and ER-resident proteins (Sun and Su, 2019). The glycosylation of CEL7A in T. reesei considerably influences its stability and secretion (Qi et al. 2014), implying the importance of glycosylation for secreted protein in ER. The correct assembly is critical for efficient cellulase production, thus, enhancing assembly through overexpression of $\mathrm{BiP} 1$ could result in higher cellulase output in T. reesei (Gao et al. 2018). However, only comparative cellulase production was achieved in a mutant with PDI1 overexpression in T. reesei (Gao et al. 2018), which might be attributed to the diverse functions of its three orthologs which coordinately work to ensure the correct folding of secreted proteins (Martinez et al. 2008).

Unfortunately, the protein folding in ER does not always follow settled procedures. Incorrect and insufficient folding would trigger its ER quality control

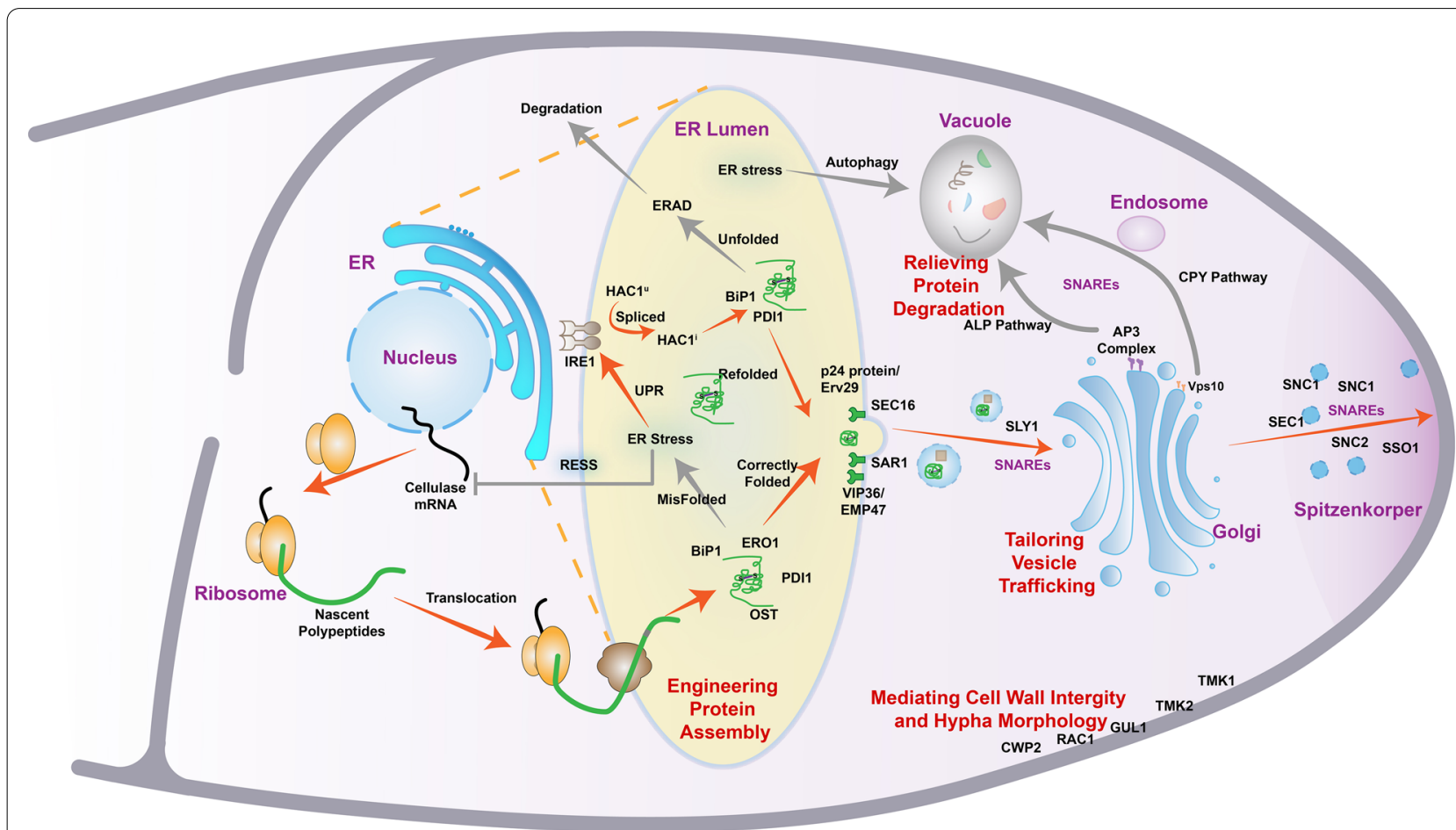

Fig. 3 Secretion pathway in T. reesei. Secreted cellulase will enter the classical secretion pathway, which passes through the ribosome, endoplasmic reticulum, Golgi, and secrets extracellularly. The ER lumen is amplified to give a comprehensive review of the protein assembly and ER quality control. The basic pathway for cellulase secretin is annotated as red arrow, with the assistance of multiple factors, including the PDI1, BiP1, HAC1, $\mathrm{SNC1}$, etc. Insufficient folding or degradation of the secreted protein is indicated by gray arrows. Moreover, the promising secretion factors for improved cellulase production in T. reesei are also annotated aside, which need further exploration. The cellular structures are marked by purple, and the promising secretion pathways for engineering are shown with red font 
mechanism and cause the retention of unfolded protein, which increases ER stress. The ER quality control is mainly maintained by unfolded protein response (UPR) which is activated through the IRE1-mediated pathway in T. reesei. The detection of incorrectly folded protein could trigger downstream UPR cascade through membranebound IRE1, which is then coupled and autophosphorylated to form an activated IRE1 (Mori 2015). Then, the activated IRE1 could act on the maturation of the mRNA of transcription factor HAC1 through splicing (Markku et al. 2003), and then induce the expression of the downstream genes for protein folding, such as pdi1, bip1, etc. Enhanced production of foreign glucose oxidase and cellulase were achieved in $T$. reesei mutants with overexpressed hac1, respectively (Gao et al. 2018; Wu et al. 2017), while another study in Pichia pastoris gave a negative result (Guerfal et al. 2010). In addition, the expression of the activated form of hac1 in Aspergillus niger is also detrimental for its growth, although the genes involved in secretion are highly upregulated (Carvalho et al. 2012). Meanwhile, the activation of UPR could also trigger endoplasmic reticulum-associated degradation (ERAD) for the degradation of unfolded proteins (Bernasconi and Molinari 2011). The knockdown of ERADrelated genes has a positive effect on protein secretion in $A$. niger, although the growth defect is also observed in its $\Delta d o a$ mutant (Carvalho et al. 2011). In T. reesei RutC30, a frameshift of the glucosidase II alpha subunit gene $(g l s 2 a)$ functioning in glucose residue removal of the early stage of ERAD might also account for the hypersecreting phenotype (Peterson and Nevalainen 2012). Moreover, an unraveled mechanism, called repression under secretion stress (RESS), is also exclusively presented in filamentous fungi for ER stress response through downregulating the transcription of major secreted proteins, such as cellulase and glucoamylase, in T. reesei (Pakula et al. 2003) and A. niger (Al-Sheikh et al. 2004), respectively. The clear mechanism for RESS has not been characterized until now, but some speculation has arisen that the RESS effect seems to function independently of the UPR (Fan et al. 2015). Moreover, it might also participate in the transcriptional regulation that a cis-element 'TCA CGGGC' motif in the $a m y B$ promoter is required for RESS in A. oryzae (Zhou et al. 2015). Besides, the deletion of adaptor protein 3 involved in alkaline phosphatase transport is also shown for decreased RESS effect, which further increases cellulase production in N. crassa (Pei et al. 2015). In addition, vacuolar/lysosomal degradative autophagy is also responsible for alleviating ER stress by directly delivering misfolded protein to the vacuole in A. oryzae (Kimura et al. 2011). Although the homologs of autophagy-related genes could also be found in T. reesei, no related reports have been published since then.
As shown above, the efficient protein assembly and the quality control mechanism in ER are critical for protein secretion. Although only a few research have been conducted in $T$. reesei, the characterized mechanism in other fungi could also give a clue for further engineering in $T$. reesei. Moreover, the effect for increased protein assembly also seemed to be related to the inner secreting stress, that the multiple-copy of secreting protein gives better results in ERAD defective mutants than that of singlecopy in A. niger (Carvalho et al. 2011). Great potential remains through manipulating protein assembly, while the exact effect and strategies still need experimental exploration.

\section{Efficient vesicle trafficking contributes to protein hypersecretion}

After intricate assembly and decoration, the folded proteins are ready for vesicle transporting which is initiated from the vesicle budding. The recognition and budding of secreting proteins are mediated by specific receptors. In $N$. crassa, p24 family proteins and Erv29p are indispensable for the delivery of the major cellulases $\mathrm{CBHI}$ and CBHII, respectively (Starr et al. 2018). Besides, increased $\alpha$-amylase secretion was achieved in $S$. cerevisiae through SEC16 overexpression, which functions in assisting budding vesicle formation (Bao et al. 2017). Meanwhile, secreted proteins can be retained by lectin-like cargo receptors AoVip36 and AoEmp47 in A. oryzae, and deletion of these receptors greatly increases the protein secretion rate by alleviating the abundance of ER-residual secreting protein (Hoang et al. 2015). Although the secretion-related protein SAR1 is also involved in bud formation, sar1 overexpression did not result in improved cellulase production in T. reesei (Gao et al. 2018).

Moreover, the vesicle trafficking from ER to the Golgi and then from Golgi to the plasma membrane is assisted via multiple SNAREs (soluble NSF [N-ethylmaleimidesensitive factor] attachment receptor proteins) (Shoji et al. 2008). Great effort has been made to increase protein secretion through improving vesicle trafficking. For example, increased glucose oxidase secretion has been achieved with overexpressed v-SNARE protein SNC1 in T. reesei (Wu et al. 2017), and the overexpression of secretion factors SSO1, SNC2, etc., is benefit for recombinant cellulase secretion in $S$. cerevisiae (Tang et al. 2017). Moreover, overexpression of Sec1/Munc18 (SM) proteins SEC1 and SLY1 facilitating vesicle trafficking increases heterologous protein production in S. cerevisiae (Hou et al. 2012). Although positive results have been achieved in different fungi with varied secreting proteins, the result through manipulating vesicle trafficking still seems to be protein-dependent (Tang et al. 2017), and it might not work on some occasions (Gao et al. 
2018). Despite the diverse results through manipulating vesicle trafficking, it remains an ideal strategy for improving cellulase production in $T$. reese $i$ which needs further verification.

\section{The biodegradation of secreting proteins in vacuole}

Occasionally, the secreted proteins were shown to be visualized in the vacuole in some cases probably due to disordered trafficking system and endoplasmic reticulum stress, which results in decreased protein production (Kimura et al. 2011; Li et al. 2019; Pang et al. 2021). The vacuole is an acidic organelle that contains multiple proteases mainly functioning in protein degradation to maintain the balance of inner environmental stability. Improved protein secretion has been achieved in a $\Delta v p s 10$ mutant in $A$. oryzae through attenuating Vps10dependent CPY pathway (Yoon et al. 2010). Similarly, our experiment also showed higher cellulase production in $\Delta v p s 10$ T. reesei compared to its parent strain (our unpublished data). Meanwhile, alleviated vacuole transport through disrupting the $\mu$ subunit of the adaptor protein 3 (AP-3) that attenuating ALP pathway could also increase cellulase production in N. crassa (Pei et al. 2015). Furthermore, in $A$. oryzae, the chymosin production increased up to threefold in autophagy gene disrupted mutants compared to that in parent strain, however, the growth and conidiation defect were also observed due to disordered degradative system (Yoon et al. 2013). Although positive results have been achieved in other fungi to lower vacuole transport for improved protein secretion, several secretion factors involved in the vacuole transport might also take part in the efficient endosomal trafficking and normal cell development (Lemmon and Traub 2000; Pei et al. 2015). Thus, it is attractive to improve cellulase production through balancing the normal cell growth and vacuole degradation in T. reesei, although few related research has been conducted since then.

\section{The hypha morphology and cell wall integrity affect protein secretion}

Traditionally, the cellulase secretion in $T$. reesei is a tipdirected process, and the secreted proteins are highly accumulated in the tip area which is annotated as Spitzenkorper (Saloheimo and Pakula 2012). Increased cellulase production has been achieved in mRNA-binding protein gul1 null mutant which increases hypha branching in T. reesei (Zhao et al. 2021). And the deletion of small Rho GTPase rac1 in T. reesei provokes hyperbranching and results in increased cellulase production on lactose (Fitz et al. 2019). Meanwhile, the transcriptome data from $\Delta g u l 1$ in $N$. crassa show the downregulation of cell wall-related genes, indicating the significance of cell wall integrity in cellulase secretion (Lin et al. 2018). The deletion of $t m k 1$ and $t m k 2$ in T. reesei involved in MAPK pathway both shows downregulation of $\beta-1,3-$ glucan synthase and higher cellulase production, while the transcription of cellulase is almost unchanged (Wang et al. 2014, 2017). In S. cerevisiae, the deletion of the cell wall-encoding gene $c w p 2$ thins the cell wall, resulting in higher CBHI secretion (Li et al. 2020). The higher production of cellulase might be attributed to a loosened cell wall thus resulting in increased secretion efficiency.

\section{Conclusion and further perspectives}

The rational engineering of filamentous fungus $T$. reese $i$ for efficient cellulase production meets the demand for economical production and higher productivity in the reality of sustainable development. Great efforts have been made to better understand the molecular mechanism behind cellulase production. And the critical steps involved in cellulase production in $T$. reesei have been broadly discussed in this review, including (1) the indispensable role of $\beta$-glucosidases and sugar transporters which control the intake and formation of inducer on cellulase induction; (2) the characterized regulators that participated in the coordinated regulation of cellulase production at the transcription level; (3) and the promising secretion pathway for engineering. The comprehensive review of the critical steps in cellulase production might give new perspectives for further exploration and engineering.

Although the characterized regulators have been successfully applied for enhancing cellulase production in T. reesei (Gao et al. 2018; Zheng et al. 2020b; Zou et al. 2018), further study still needs to focus on the elucidation and investigation of biological function of annotated regulators which are the promising candidates for enhanced cellulase production in engineered T. reesei. Moreover, the design of new synthetic circuits could be a benefit for cellulase production (Zhang et al. 2018b), which gives the possibility that the design of synthetic inducing pathways tightly controlling the inducer uptake and accumulation. In addition, the development of the dynamic circuits via the utilization of conditional promoters, for example, the copper-dependent promoter Ptcu in T. reesei (Lv et al. 2015), thiamine-derepressed promoter Pthi in A. ory$z a e$ (Yoon et al. 2013) as well as the exploration of stress-induced or growth-coupled promoters could give a dynamic regulation on cellulase induction and transcriptional regulation, which might mimic the real inducing cascade in $T$. reese $i$. Then, the investigation of potential candidates for enhanced cellulase production still needs efficient screening via transcriptome exploration and genomic search (Liu et al. 2019a), as well 
as rapid genetic manipulation through novel molecular tools such as the CRISPR/Cas9 (Liu et al. 2015). Besides, the secretion pathway which is also critical for efficient cellulase production was hardly explored in $T$. reesei, and this area was far from full investigation even in filamentous fungi, which gives a clue for further exploration. However, the dynamic endosomal system in secretion pathway is related to cell growth and morphology, thus it is important to engineer cellulase secretion in a more flexible and dynamic strategy. In the future, we expect a deeper understanding and diversified methods to improve cellulase production and meet the demand for cellulase utilization in T. reesei.

\section{Abbreviations}

CCR: Carbon catabolite repression; TF: Transcription factor; PHD: Plant homeo domain; MAPK: Mitogen-activated protein kinase; WCC: White-collar complex; CRZ1: Calcineurin-responsive zinc finger transcription factor 1; DMF: $\mathrm{N}, \mathrm{N}$-Dimethylformamide; ER: Endoplasmic reticulum; UPR: Unfolded protein response; ERAD: Endoplasmic reticulum-associated degradation; RESS: Repression under secretion stress.

\section{Acknowledgements}

Not applicable.

\section{Authors' contributions}

SY, YX and XWY designed the study. SY and XWY collected the data and wrote the paper. All authors read and approved the final manuscript.

\section{Fundings}

This work is supported by the National Key Research and Development Program of China (2021YFC2100203); the National Natural Science Foundation of China (32072162); Postgraduate Research \& Practice Innovation Program of Jiangsu Province (KYCX20_1819); National First-Class Discipline Program of Light Industry Technology and Engineering (LITE2018-09) and 111 Project $(111-2-06)$

\section{Availability of data and materials}

All data generated or analyzed during this study are included in this published article, or upon request from the corresponding author.

\section{Declarations}

Ethics approval and consent to participate

Not applicable.

\section{Consent for publication}

Not applicable.

\section{Competing interests}

The authors declare that they have no known competing financial interests or personal relationships that could have appeared to influence the work reported in this paper.

\section{Author details}

'Lab of Brewing Microbiology and Applied Enzymology, School of Biotechnology, Jiangnan University, Wuxi 214122, People's Republic of China. ${ }^{2}$ Key Laboratory of Industrial Biotechnology, Ministry of Education, School of Biotechnology, Jiangnan University, Wuxi 214122, People's Republic of China.

Received: 8 September 2021 Accepted: 16 October 2021

Published online: 22 October 2021
References

Al-Sheikh H, Watson AJ, Lacey GA, Punt PJ, MacKenzie DA, Jeenes DJ, Pakula T, Penttila M, Alcocer MJ, Archer DB (2004) Endoplasmic reticulum stress leads to the selective transcriptional downregulation of the glucoamylase gene in Aspergillus niger. Mol Microbiol 53:1731-1742

Antonieto ACC, Nogueira KMV, de Paula RG, Nora LC, Cassiano MHA, Guazzaroni ME, Almeida F, da Silva TA, Ries LNA, de Assis LJ, Goldman GH, Silva RN, Silva-Rocha R (2019) A novel Cys2His2 zinc finger homolog of AZF1 modulates holocellulase expression in Trichoderma reesei. Msystems. 4:e00161-e219

Bao J, Huang M, Petranovic D, Nielsen J (2017) Moderate expression of SEC16 increases protein secretion by Saccharomyces cerevisiae. Appl Environ Microbiol 83:e03400-e3416

Bayram O, Braus GH (2012) Coordination of secondary metabolism and development in fungi: the velvet family of regulatory proteins. FEMS Microbiol Rev 36:1-24

Beier S, Hinterdobler W, Bazafkan H, Schillinger L, Schmoll M (2020a) CLR1 and CLR2 are light dependent regulators of xylanase and pectinase genes in Trichoderma reesei. Fungal Genet Biol 136:103315

Beier S, Hinterdobler W, Monroy AA, Bazafkan H, Schmoll M (2020b) The Kinase USK1 Regulates Cellulase Gene Expression and Secondary Metabolite Biosynthesis in Trichoderma reesei. Front Microbiol 11:974

Bernasconi R, Molinari M (2011) ERAD and ERAD tuning: disposal of cargo and of ERAD regulators from the mammalian ER. Curr Opin Cell Biol 23:176-183

Bischof RH, Ramoni J, Seiboth B (2016) Cellulases and beyond: the first 70 years of the enzyme producer Trichoderma reesei. Microb Cell Fact 15:106

Cao Y, Zheng F, Wang L, Zhao G, Chen G, Zhang W, Liu W (2017) Rce1, a novel transcriptional repressor, regulates cellulase gene expression by antagonizing the transactivator Xyr1 in Trichoderma reesei. Mol Microbiol 105:65-83

Cao Y, Zheng F, Zhang W, Meng X, Liu W (2019) Trichoderma reesei XYR1 recruits SWI/SNF to facilitate cellulase gene expression. Mol Microbiol 112:1145-1162

Carvalho ND, Arentshorst M, Kooistra R, Stam H, Sagt CM, van den Hondel CA, Ram AF (2011) Effects of a defective ERAD pathway on growth and heterologous protein production in Aspergillus niger. Appl Microbiol Biotechnol 89:357-373

Carvalho ND, Jorgensen TR, Arentshorst M, Nitsche BM, van den Hondel CA, Archer DB, Ram AF (2012) Genome-wide expression analysis upon constitutive activation of the HacA bZIP transcription factor in Aspergillus niger reveals a coordinated cellular response to counteract ER stress. BMC Genomics 13:350

Castellanos F, Schmoll M, Martinez P, Tisch D, Kubicek CP, Herrera-Estrella A, Esquivel-Naranjo EU (2010) Crucial factors of the light perception machinery and their impact on growth and cellulase gene transcription in Trichoderma reesei. Fungal Genet Biol 47:468-476

Celinska E, Nicaud JM (2019) Filamentous fungi-like secretory pathway strayed in a yeast system: peculiarities of Yarrowia lipolytica secretory pathway underlying its extraordinary performance. Appl Microbiol Biotechnol 103:39-52

Chen L, Zou G, Wang J, Wang J, Liu R, Jiang Y, Zhao G, Zhou Z (2016) Characterization of the $\mathrm{Ca}(2+)$-responsive signaling pathway in regulating the expression and secretion of cellulases in Trichoderma reesei Rut-C30. Mol Microbiol 100:560-575

Chen Y, Shen Y, Wang W, Wei D (2018) Mn(2+) modulates the expression of cellulase genes in Trichoderma reesei Rut-C30 via calcium signaling. Biotechnol Biofuels 11:54

Chen Y, Wu C, Shen Y, Ma Y, Wei D, Wang W (2019) N, N-dimethylformamide induces cellulase production in the filamentous fungus Trichoderma reesei. Biotechnol Biofuels 12:36

Chen Y, Fan X, Zhao X, Shen Y, Xu X, Wei L, Wang W, Wei D (2021a) cAMP activates calcium signalling via phospholipase $C$ to regulate cellulase production in the filamentous fungus Trichoderma reesei. Biotechnol Biofuels 14:62

Chen Y, Lin A, Liu P, Fan X, Wu C, Li N, Wei L, Wang W, Wei D (2021 b) Trichoderma reesei ACE4, a novel transcriptional activator involved in the regulation of cellulase genes during growth on cellulose. Appl Environ Microbiol 87:e0059321 
Chen Y, Wang W, Liu P, Lin A, Fan X, Wu C, Li N, Wei L, Wei D (2021c) The novel repressor Rce2 competes with Ace 3 to regulate cellulase gene expression in the filamentous fungus Trichoderma reesei. Mol Microbiol. https://doi.org/10.1111/mmi.14825

Cherry JR, Fidantsef AL (2003) Directed evolution of industrial enzymes: an update. Curr Opin Biotechnol 14:438-443

Conesa A, Punt PJ, van Luijk N, van den Hondel CA (2001) The secretion pathway in filamentous fungi: a biotechnological view. Fungal Genet Biol 33:155-171

Coradetti ST, Craig JP, Xiong Y, Shock T, Tian C, Glass NL (2012) Conserved and essential transcription factors for cellulase gene expression in ascomycete fungi. Proc Natl Acad Sci U S A 109:7397-7402

Cziferszky A, Mach RL, Kubicek CP (2002) Phosphorylation positively regulates DNA binding of the carbon catabolite repressor Cre1 of Hypocrea jecorina (Trichoderma reesei). J Biol Chem 277:14688-14694

de Assis LJ, Silva LP, Bayram O, Dowling P, Kniemeyer O, Kruger T, Brakhage AA, Chen Y, Dong L, Tan K, Wong KH, Ries LNA, Goldman GH (2021) Carbon catabolite repression in filamentous fungi is regulated by phosphorylation of the transcription factor CreA. Mbio 12:e03146-e3220

de Paula RG, Antonieto ACC, Ribeiro LFC, Carraro CB, Nogueira KMV, Lopes DCB, Silva AC, Zerbini MT, Pedersoli WR, Costa MDN, Silva RN (2018) New Genomic Approaches to Enhance Biomass Degradation by the Industrial Fungus Trichoderma reesei. Int J Genomics 2018:1974151

Derntl C, Rassinger A, Srebotnik E, Mach RL, Mach-Aigner AR (2016) Identification of the Main Regulator Responsible for Synthesis of the Typical Yellow Pigment Produced by Trichoderma reesei. Appl Environ Microbiol 82:6247-6257

Dos Santos Castro L, de Paula RG, Antonieto AC, Persinoti GF, Silva-Rocha R, Silva RN (2016) Understanding the Role of the Master Regulator XYR1 in Trichoderma reesei by Global Transcriptional Analysis. Front Microbiol 7:175

Druzhinina IS, Kubicek CP (2017) Genetic engineering of Trichoderma reesei cellulases and their production. Microb Biotechnol 10:1485-1499

Espeso EA, Tilburn J, Sanchez-Pulido L, Brown CV, Valencia A, Arst HN Jr, Penalva MA (1997) Specific DNA recognition by the Aspergillus nidulans three zinc finger transcription factor PacC. J Mol Biol 274:466-480

Fan F, Ma G, Li J, Liu Q, Benz JP, Tian C, Ma Y (2015) Genome-wide analysis of the endoplasmic reticulum stress response during lignocellulase production in Neurospora crassa. Biotechnol Biofuels 8:66

Fitz E, Gamauf C, Seiboth B, Wanka F (2019) Deletion of the small GTPase rac1 in Trichoderma reesei provokes hyperbranching and impacts growth and cellulase production. Fungal Biol Biotechnol 6:16

Fowler T, Brown RD Jr (1992) The bg/1 gene encoding extracellular $\beta$-glucosidase from Trichoderma reesei is required for rapid induction of the cellulase complex. Mol Microbiol 6:3225-3235

Gao F, Hao Z, Sun X, Qin L, Zhao T, Liu W, Luo H, Yao B, Su X (2018) A versatile system for fast screening and isolation of Trichoderma reesei cellulase hyperproducers based on DsRed and fluorescence-assisted cell sorting. Biotechnol Biofuels 11:261

Guerfal M, Ryckaert S, Jacobs PP, Ameloot P, Van Craenenbroeck K, Derycke R, Callewaert N (2010) The HAC1 gene from Pichia pastoris: characterization and effect of its overexpression on the production of secreted, surface displayed and membrane proteins. Microb Cell Fact 9:49

Guo B, Sato N, Biely P, Amano Y, Nozaki K (2016) Comparison of catalytic properties of multiple $\beta$-glucosidases of Trichoderma reesei. Appl Microbiol Biotechnol 100:4959-4968

Gupta VK, Steindorff AS, de Paula RG, Silva-Rocha R, Mach-Aigner AR, Mach RL, Silva RN (2016) The Post-genomic Era of Trichoderma reesei: What's Next? Trends Biotechnol 34:970-982

Hagiwara D, Kondo A, Fujioka T, Abe K (2008) Functional analysis of C2H2 zinc finger transcription factor CrzA involved in calcium signaling in Aspergillus nidulans. Curr Genet 54:325-338

Hakkinen M, Arvas M, Oja M, Aro N, Penttila M, Saloheimo M, Pakula TM (2012) Re-annotation of the CAZy genes of Trichoderma reesei and transcription in the presence of lignocellulosic substrates. Microb Cell Fact 11:134

Hakkinen M, Sivasiddarthan D, Aro N, Saloheimo M, Pakula TM (2015) The effects of extracellular $\mathrm{pH}$ and of the transcriptional regulator PACl on the transcriptome of Trichoderma reesei. Microb Cell Fact 14:63
Han L, Liu K, Ma W, Jiang Y, Hou S, Tan Y, Yuan Q, Niu K, Fang X (2020a) Redesigning transcription factor Cre1 for alleviating carbon catabolite repression in Trichoderma reesei. Synth Syst Biotechnol 5:230-235

Han L, Tan Y, Ma W, Niu K, Hou S, Guo W, Liu Y, Fang X (2020b) Precision Engineering of the Transcription Factor Cre1 in Hypocrea jecorina (Trichoderma reesei) for Efficient Cellulase Production in the Presence of Glucose. Front Bioeng Biotech 8:852

Havukainen S, Valkonen M, Koivuranta K, Landowski CP (2020) Studies on sugar transporter CRT1 reveal new characteristics that are critical for cellulase induction in Trichoderma reesei. Biotechnol Biofuels 13:158

He R, Ma L, Li C, Jia W, Li D, Zhang D, Chen S (2014) Trpac1, a pH response transcription regulator, is involved in cellulase gene expression in Trichoderma reesei. Enzyme Microb Technol 67:17-26

Hernández-Ortiz P, Espeso EA (2013) Phospho-regulation and nucleocytoplasmic trafficking of CrzA in response to calcium and alkaline-pH stress in Aspergillus nidulans. Mol Microbiol 89:532-551

Hoang HD, Maruyama J, Kitamoto K (2015) Modulating endoplasmic reticulum-Golgi cargo receptors for improving secretion of carrierfused heterologous proteins in the filamentous fungus Aspergillus oryzae. Appl Environ Microbiol 81:533-543

Hou J, Tyo K, Liu Z, Petranovic D, Nielsen J (2012) Engineering of vesicle trafficking improves heterologous protein secretion in Saccharomyces cerevisiae. Metab Eng 14:120-127

Ivanova C, Ramoni J, Aouam T, Frischmann A, Seiboth B, Baker SE, Le Crom S, Lemoine S, Margeot A, Bidard F (2017) Genome sequencing and transcriptome analysis of Trichoderma reesei QM9978 strain reveals a distal chromosome translocation to be responsible for loss of vib1 expression and loss of cellulase induction. Biotechnol Biofuels 10:209

Karaffa L, Fekete E, Gamauf C, Szentirmai A, Kubicek CP, Seiboth B (2006) D-Galactose induces cellulase gene expression in Hypocrea jecorina at low growth rates. Microbiol-Sgm 152:1507-1514

Karaffa L, Coulier L, Fekete E, Overkamp KM, Druzhinina IS, Mikus M, Seiboth B, Novak L, Punt PJ, Kubicek CP (2013) The intracellular galactoglycome in Trichoderma reesei during growth on lactose. Appl Microbiol Biotechnol 97:5447-5456

Karimi Aghcheh R, Nemeth Z, Atanasova L, Fekete E, Paholcsek M, Sandor E, Aquino B, Druzhinina IS, Karaffa L, Kubicek CP (2014) The VELVET A orthologue VEL1 of Trichoderma reesei regulates fungal development and is essential for cellulase gene expression. PLOS ONE 9:e112799

Kiesenhofer DP, Mach RL, Mach-Aigner AR (2018) Influence of cis Element Arrangement on Promoter Strength in Trichoderma reesei. Appl Environ Microbiol 84:e01742-e1817

Kimura S, Maruyama J, Kikuma T, Arioka M, Kitamoto K (2011) Autophagy delivers misfolded secretory proteins accumulated in endoplasmic reticulum to vacuoles in the filamentous fungus Aspergillus oryzae. Biochem Biophys Res Commun 406:464-470

Kubicek CP, Mikus M, Schuster A, Schmoll M, Seiboth B (2009) Metabolic engineering strategies for the improvement of cellulase production by Hypocrea jecorina. Biotechnol Biofuels 2:19

Lemmon SK, Traub LM (2000) Sorting in the endosomal system in yeast and animal cells. Curr Opin Cell Biol 12:457-466

Li C, Yang Z, Zhang RH, Zhang D, Chen S, Ma L (2013) Effect of pH on cellulase production and morphology of Trichoderma reesei and the application in cellulosic material hydrolysis. J Biotechnol 168:470-477

Li C, Lin F, Li Y, Wei W, Wang H, Qin L, Zhou Z, Li B, Wu F, Chen Z (2016) A beta-glucosidase hyper-production Trichoderma reesei mutant reveals a potential role of cel3D in cellulase production. Microb Cell Fact 15:151

Li C, Lin F, Zhou L, Qin L, Li B, Zhou Z, Jin M, Chen Z (2017) Cellulase hyper-production by Trichoderma reesei mutant SEU-7 on lactose. Biotechnol Biofuels 10:228

Li C, Pang AP, Yang H, Lv R, Zhou Z, Wu FG, Lin F (2019) Tracking localization and secretion of cellulase spatiotemporally and directly in living Trichoderma reesei. Biotechnol Biofuels 12:200

Li J, Zhang MM, Wan C, Den Haan R, Bai FW, Zhao XQ (2020) Improved cellulase production in recombinant Saccharomyces cerevisiae by disrupting the cell wall protein-encoding gene CWP2. J Biosci Bioeng 129:165-171 
Lin L, Sun Z, Li J, Chen Y, Liu Q, Sun W, Tian C (2018) Disruption of gul-1 decreased the culture viscosity and improved protein secretion in the filamentous fungus Neurospora crassa. Microb Cell Fact 17:96

Liu G, Qu Y (2019) Engineering of filamentous fungi for efficient conversion of lignocellulose: Tools, recent advances and prospects. Biotechnol Adv 37:519-529

Liu R, Chen L, Jiang Y, Zhou Z, Zou G (2015) Efficient genome editing in filamentous fungus Trichoderma reesei using the CRISPR/Cas9 system. Cell Discov 1:15007

Liu K, Dong Y, Wang F, Jiang B, Wang M, Fang X (2016) Regulation of cellulase expression, sporulation, and morphogenesis by velvet family proteins in Trichoderma reesei. Appl Microbiol Biotechnol 100:769-779

Liu P, Lin A, Zhang G, Zhang J, Chen Y, Shen T, Zhao J, Wei D, Wang W (2019a) Enhancement of cellulase production in Trichoderma reesei RUT-C30 by comparative genomic screening. Microb Cell Fact 18:81

Liu P, Zhang G, Chen Y, Zhao J, Wang W, Wei D (2019b) Enhanced cellulase production by decreasing intercellular $\mathrm{pH}$ through $\mathrm{H}(+)$-ATPase gene deletion in Trichoderma reesei RUT-C30. Biotechnol Biofuels 12:195

Lv X, Zheng F, Li C, Zhang W, Chen G, Liu W (2015) Characterization of a copper responsive promoter and its mediated overexpression of the xylanase regulator 1 results in an induction-independent production of cellulases in Trichoderma reesei. Biotechnol Biofuels 8:67

Mach RL, Seiboth B, Myasnikov A, Gonzalez R, Strauss J, Harkki AM, Kubicek CP (1995) The bgll gene of Trichoderma reesei QM 9414 encodes an extracellular, cellulose-inducible $\beta$-glucosidase involved in cellulase induction by sophorose. Mol Microbiol 16:687-697

Mandels M, Reese ET (1957) Induction of cellulase in Trichoderma viride as influenced by carbon sources and metals. J Bacteriol 73:269-278

Mandels M, Reese ET (1960) Induction of cellulase in fungi by cellobiose. J Bacteriol 79:816-826

Markku S, Mari V, Merja P (2003) Activation mechanisms of the HAC1-mediated unfolded protein response in filamentous fungi. Mol Microbiol 47:1149-1161

Martinez D, Berka RM, Henrissat B, Saloheimo M, Arvas M, Baker SE, Chapman J, Chertkov O, Coutinho PM, Cullen D, Danchin EG, Grigoriev IV Harris P, Jackson M, Kubicek CP, Han CS, Ho I, Larrondo LF, de Leon AL, Magnuson JK, Merino S, Misra M, Nelson B, Putnam N, Robbertse B, Salamov AA, Schmoll M, Terry A, Thayer N, Westerholm-Parvinen A, Schoch CL, Yao J, Barabote R, Nelson MA, Detter C, Bruce D, Kuske CR, Xie G, Richardson P, Rokhsar DS, Lucas SM, Rubin EM, Dunn-Coleman N, Ward M, Brettin TS (2008) Genome sequencing and analysis of the biomass-degrading fungus Trichoderma reesei (syn. Hypocrea jecorina). Nat Biotechnol 26:553-560

Meng QS, Zhang F, Liu CG, Zhao XQ, Bai FW (2020) Identification of a novel repressor encoded by the putative gene ctf1 for cellulase biosynthesis in Trichoderma reesei through artificial zinc finger engineering. Biotechnol Bioeng 117:1747-1760

Mori K (2015) The unfolded protein response: the dawn of a new field. Proc. J.jn Acad Ser B Phys Biol Sci 91:469-480

Nitta M, Furukawa T, Shida Y, Mori K, Kuhara S, Morikawa Y, Ogasawara W (2012) A new Zn(II)(2)Cys(6)-type transcription factor BgIR regulates beta-glucosidase expression in Trichoderma reesei. Fungal Genet Biol 49:388-397

Nogueira KMV, de Paula RG, Antonieto ACC, Dos Reis TF, Carraro CB, Silva AC, Almeida F, Rechia CGV, Goldman GH, Silva RN (2018) Characterization of a novel sugar transporter involved in sugarcane bagasse degradation in Trichoderma reesei. Biotechnol Biofuels 11:84

Nogueira KMV, Mendes V, Carraro CB, Taveira IC, Oshiquiri LH, Gupta VK, Silva RN (2020) Sugar transporters from industrial fungi: Key to improving second-generation ethanol production. Renew. Sust. Energ. Rev. 131:109991

Pakula TM, Laxell M, Huuskonen A, Uusitalo J, Saloheimo M, Penttila M (2003) The effects of drugs inhibiting protein secretion in the filamentous fungus Trichoderma reesei. Evidence for down-regulation of genes that encode secreted proteins in the stressed cells. J Biol Chem 278:45011-45020

Pang AP, Wang H, Luo Y, Yang Z, Liu Z, Wang Z, Li B, Yang S, Zhou Z, Lu X, Wu FG, Lu Z, Lin F (2021) Dissecting cellular function and distribution of beta-glucosidases in Trichoderma reesei. Mbio 12:e03671-e3720

Pei X, Fan F, Lin L, Chen Y, Sun W, Zhang S, Tian C (2015) Involvement of the adaptor protein 3 complex in lignocellulase secretion in Neurospora crassa revealed by comparative genomic screening. Biotechnol Biofuels 8:124

Peterson R, Nevalainen H (2012) Trichoderma reesei RUT-C30-thirty years of strain improvement. Microbiology 158:58-68

Porciuncula JD, Furukawa T, Shida Y, Mori K, Kuhara S, Morikawa Y, Ogasawara W (2013) Identification of major facilitator transporters involved in cellulase production during lactose culture of Trichoderma reesei PC-3-7. Biosci Biotech Bioch 77:1014-1022

Portnoy T, Margeot A, Linke R, Atanasova L, Fekete E, Sandor E, Hartl L, Karaffa L, Druzhinina IS, Seiboth B, Le Crom S, Kubicek CP (2011a) The CRE1 carbon catabolite repressor of the fungus Trichoderma reesei: a master regulator of carbon assimilation. BMC Genomics 12:269

Portnoy T, Margeot A, Seidl-Seiboth V, Le Crom S, Ben Chaabane F, Linke R, Seiboth B, Kubicek CP (2011 b) Differential regulation of the cellulase transcription factors XYR1, ACE2, and ACE1 in Trichoderma reesei strains producing high and low levels of cellulase. Eukaryot Cell 10:262-271

Qi F, Zhang W, Zhang F, Chen G, Liu W (2014) Deciphering the effect of the different $\mathrm{N}$-glycosylation sites on the secretion, activity, and stability of cellobiohydrolase I from Trichoderma reesei. Appl Environ Microbiol 80:3962-3971

Qian Y, Sun Y, Zhong L, Sun N, Sheng Y, Qu Y, Zhong Y (2019) The GATA-Type Transcriptional Factor Are1 Modulates the Expression of Extracellular Proteases and Cellulases in Trichoderma reesei. Int J Mol Sci 20:15

Ries L, Pullan ST, Delmas S, Malla S, Blythe MJ, Archer DB (2013) Genome-wide transcriptional response of Trichoderma reesei to lignocellulose using RNA sequencing and comparison with Aspergillus niger. BMC Genomics 14:541

Ries L, Belshaw NJ, IImen M, Penttila ME, Alapuranen M, Archer DB (2014) The role of CRE1 in nucleosome positioning within the cbhl promoter and coding regions of Trichoderma reesei. Appl Microbiol Biotechnol 98:749-762

Saloheimo M, Pakula TM (2012) The cargo and the transport system: secreted proteins and protein secretion in Trichoderma reesei (Hypocrea jecorina). Microbiology 158:46-57

Saloheimo A, Aro N, Ilmen M, Penttila M (2000) Isolation of the acel gene encoding a Cys(2)-His(2) transcription factor involved in regulation of activity of the cellulase promoter cbh1 of Trichoderma reesei. J Biol Chem 275:5817-5825

Schmoll M (2018) Light, stress, sex and carbon - The photoreceptor ENVOY as a central checkpoint in the physiology of Trichoderma reesei. Fungal Biol 122:479-486

Schmoll M, Franchi L, Kubicek CP (2005) Envoy, a PAS/LOV domain protein of Hypocrea jecorina (Anamorph Trichoderma reesei), modulates cellulase gene transcription in response to light. Eukaryot Cell 4:1998-2007

Schmoll M, Schuster A, Silva Rdo N, Kubicek CP (2009) The G-alpha protein GNA3 of Hypocrea jecorina (Anamorph Trichoderma reesei) regulates cellulase gene expression in the presence of light. Eukaryot Cell 8:410-420

Schuster A, Tisch D, Seidl-Seiboth V, Kubicek CP, Schmoll M (2012) Roles of protein kinase $A$ and adenylate cyclase in light-modulated cellulase regulation in Trichoderma reesei. Appl Environ Microbiol 78:2168-2178

Seibel, C., Gremel, G., do Nascimento Silva, R., Schuster, A., Kubicek, C.P., Schmoll, M. 2009. Light-dependent roles of the G-protein a subunit GNA1 of Hypocrea jecorina (anamorph Trichoderma reesei) BMC Biol. 7 , 58.

Seiboth B, Hartl L, Salovuori N, Lanthaler K, Robson GD, Vehmaanperä J, Penttilä ME, Kubicek CP (2005) Role of the bga1-encoded extracellular $\beta$-galactosidase of Hypocrea jecorina in cellulase induction by lactose. Appl Environ Microbiol 71:851-857

Seiboth B, Gamauf C, Pail M, Hartl L, Kubicek C (2007) The major D-xylose reductase of Hypocrea jecorina is necessary for efficient pentose and lactose catabolism and for cellulase induction by lactose. Mol Microbiol 66:890-900

Seiboth B, Karimi RA, Phatale PA, Linke R, Hartl L, Sauer DG, Smith KM, Baker SE, Freitag M, Kubicek CP (2012) The putative protein methyltransferase LAE1 controls cellulase gene expression in Trichoderma reesei. Mol Microbiol 84:1150-1164

Shibata N, Kakeshita H, Igarashi K, Takimura Y, Shida Y, Ogasawara W, Koda T, Hasunuma T, Kondo A (2021) Disruption of alpha-tubulin releases carbon catabolite repression and enhances enzyme production in Trichoderma reesei even in the presence of glucose. Biotechnol Biofuels 14:39 
Shida Y, Yamaguchi K, Nitta M, Nakamura A, Takahashi M, Kidokoro S, Mori K, Tashiro K, Kuhara S, Matsuzawa T, Yaoi K, Sakamoto Y, Tanaka N, Morikawa Y, Ogasawara W (2015) The impact of a single-nucleotide mutation of bg/2 on cellulase induction in a Trichoderma reesei mutant. Biotechnol Biofuels 8:230

Shoji JY, Arioka M, Kitamoto K (2008) Dissecting cellular components of the secretory pathway in filamentous fungi: insights into their application for protein production. Biotechnol Lett 30:7-14

Sloothaak J, Tamayo-Ramos JA, Odoni DI, Laothanachareon T, Derntl C, MachAigner AR, Martins Dos Santos VAP, Schaap PJ (2016) Identification and functional characterization of novel xylose transporters from the cell factories Aspergillus niger and Trichoderma reesei. Biotechnol Biofuels 9:148

Smith KM, Sancar G, Dekhang R, Sullivan CM, Li S, Tag AG, Sancar C, Bredeweg EL, Priest HD, McCormick RF, Thomas TL, Carrington JC, Stajich JE, BellPedersen D, Brunner M, Freitag M (2010) Transcription factors in light and circadian clock signaling networks revealed by genomewide mapping of direct targets for neurospora white collar complex. Eukaryot Cell 9:1549-1556

Starr TL, Gonçalves AP, Meshgin N, Glass NL (2018) The major cellulases CBH-1 and $\mathrm{CBH}-2$ of Neurospora crassa rely on distinct ER cargo adaptors for efficient ER-exit. Mol Microbiol 107:229-248

Sternberg D, Mandels GR (1979) Induction of cellulolytic enzymes in Trichoderma reesei by sophorose. J Bacteriol 139:761-769

Stricker AR, Steiger MG, Mach RL (2007) Xyr1 receives the lactose induction signal and regulates lactose metabolism in Hypocrea jecorina. FEBS Lett 581:3915-3920

Sun X, Su X (2019) Harnessing the knowledge of protein secretion for enhanced protein production in filamentous fungi. World I Microbiol Biotechnol 35:54

Sun X, Zhang X, Huang H, Wang Y, Tu T, Bai Y, Wang Y, Zhang J, Luo H, Yao B, SuX (2020) Engineering the cbh1 promoter of Trichoderma reesei for enhanced protein production by replacing the binding sites of a transcription repressor ACE1 to those of the activators. J Agric Food Chem 68:1337-1346

Tang H, Song M, He Y, Wang J, Wang S, Shen Y, Hou J, Bao X (2017) Engineering vesicle trafficking improves the extracellular activity and surface display efficiency of cellulases in Saccharomyces cerevisiae. Biotechnol Biofuels 10:53

Tisch D, Schuster A, Schmoll M (2014) Crossroads between light response and nutrient signalling: ENV1 and PhLP1 act as mutual regulatory pair in Trichoderma reesei. BMC Genomics 15:425

Wang M, Zhao Q, Yang J, Jiang B, Wang F, Liu K, Fang X (2013) A mitogen-activated protein kinase Tmk3 participates in high osmolarity resistance, cell wall integrity maintenance and cellulase production regulation in Trichoderma reesei. PLOS ONE 8:e72189

Wang M, Dong Y, Zhao Q, Wang F, Liu K, Jiang B, Fang X (2014) Identification of the role of a MAP kinase Tmk2 in Hypocrea jecorina (Trichoderma reesei). Sci Rep 4:6732

Wang M, Zhang M, Li L, Dong Y, Jiang Y, Liu K, Zhang R, Jiang B, Niu K, Fang $X$ (2017) Role of Trichoderma reesei mitogen-activated protein kinases (MAPKs) in cellulase formation. Biotechnol Biofuels 10:99

Wang L, Lv X, Cao Y, Zheng F, Meng X, Shen Y, Chen G, Liu W, Zhang W (2019a) A novel transcriptional regulator RXE1 modulates the essential transactivator XYR1 and cellulase gene expression in Trichoderma reesei. Appl Microbiol Biotechnol 103:4511-4523

Wang L, Yang R, Cao Y, Zheng F, Meng X, Zhong Y, Chen G, Zhang W, Liu W (2019b) CLP1, a novel plant homeo domain protein, participates in regulating cellulase gene expression in the filamentous fungus Trichoderma reesei. Front Microbiol 10:1700

Wang Q, Zhong C, Xiao H (2020) Genetic engineering of filamentous fungi for efficient protein expression and secretion. Front Bioeng Biotechnol $8: 293$

Wu Y, Sun X, Xue X, Luo H, Yao B, Xie X, Su X (2017) Overexpressing key component genes of the secretion pathway for enhanced secretion of an Aspergillus niger glucose oxidase in Trichoderma reesei. Enzyme Microb Technol 106:83-87
Xin Q, Gong Y, Lv X, Chen G, Liu W (2013) Trichoderma reesei histone acetyltransferase Gcn5 regulates fungal growth, conidiation, and cellulase gene expression. Curr Microbiol 67:580-589

XU J, Zhao G, Kou Y, Zhang W, Zhou Q, Chen G, Liu W (2014) Intracellular $\beta$-glucosidases CEL1a and CEL1b are essential for cellulase induction on lactose in Trichoderma reesei. Eukaryot Cell 13:1001-1013

Yan S, Xu Y, Yu XW (2021) Rational engineering of xylanase hyper-producing system in Trichoderma reesei for efficient biomass degradation. Biotechnol Biofuels 14:90

Yoon J, Aishan T, Maruyama J, Kitamoto K (2010) Enhanced production and secretion of heterologous proteins by the filamentous fungus Aspergillus oryzae via disruption of vacuolar protein sorting receptor gene Aovps 10. Appl Environ Microbiol 76:5718-5727

Yoon J, Kikuma T, Maruyama J, Kitamoto K (2013) Enhanced production of bovine chymosin by autophagy deficiency in the filamentous fungus Aspergillus oryzae. PLoS ONE 8:e62512

Zeilinger S, Schmoll M, Pail M, Mach RL, Kubicek CP (2003) Nucleosome transactions on the Hypocrea jecorina (Trichoderma reesei) cellulase promoter cbh2 associated with cellulase induction. Mol Genet Genomics 270:46-55

Zhang WX, Kou YB, Xu JT, Cao YL, Zhao GL, Shao J, Wang H, Wang ZX, Bao XM, Chen GJ, Liu WF (2013) Two major facilitator superfamily sugar transporters from Trichoderma reesei and their roles in induction of cellulase biosynthesis. J Biol Chem 288:32861-32872

Zhang F, Zhao X, Bai F (2018a) Improvement of cellulase production in Trichoderma reesei Rut- $\mathrm{C} 30$ by overexpression of a novel regulatory gene Trvib-1. Bioresour Technol 247:676-683

Zhang J, Zhang G, Wang W, Wang W, Wei D (2018b) Enhanced cellulase production in Trichoderma reesei RUT C30 via constitution of minimal transcriptional activators. Microb Cell Fact 17:75

Zhang J, Chen Y, Wu C, Liu P, Wang W, Wei D (2019) The transcription factor ACE3 controls cellulase activities and lactose metabolism via two additional regulators in the fungus Trichoderma reesei. J Biol Chem 294:18435-18450

Zhang W, An N, Guo J, Wang Z, Meng X, Liu W (2021) Influences of genetically perturbing synthesis of the typical yellow pigment on conidiation, cell wall integrity, stress tolerance, and cellulase production in Trichoderma reesei. J Microbiol 59:426-434

Zhao Q, Liu Q, Wang Q, Qin Y, Zhong Y, Gao L, Liu G, Qu Y (2021) Disruption of the Trichoderma reesei gull gene stimulates hyphal branching and reduces broth viscosity in cellulase production. J Ind Microbiol Biotechnol. https://doi.org/10.1093/jimb/kuab012

Zheng F, Cao Y, Yang R, Wang L, Lv X, Zhang W, Meng X, Liu W (2020a) Trichoderma reesei $X Y R 1$ activates cellulase gene expression via interaction with the Mediator subunit TrGAL11 to recruit RNA polymerase II. PLoS Genet 16:e1008979

Zheng F, Yang R, Cao Y, Zhang W, Lv X, Meng X, Zhong Y, Chen G, Zhou Q, Liu W (2020b) Engineering Trichoderma reesei for hyperproduction of cellulases on glucose to efficiently saccharify pretreated corncobs. J Agr Food Chem 68:12671-12682

Zhou Q, Xu J, Kou Y, Lv X, Zhang X, Zhao G, Zhang W, Chen G, Liu W (2012) Differential involvement of $\beta$-glucosidases from Hypocrea jecorina in rapid induction of cellulase genes by cellulose and cellobiose. Eukaryot Cell 11:1371-1381

Zhou B, Wang C, Wang B, Li X, Xiao J, Pan L (2015) Identification of functional cis-elements required for repression of the Taka-amylase A gene under secretion stress in Aspergillus oryzae. Biotechnol Lett 37:333-341

Zou G, Jiang Y, Liu R, Zhu Z, Zhou Z (2018) The putative $\beta$-glucosidase BGL3I regulates cellulase induction in Trichoderma reesei. Biotechnol Biofuels $11: 314$

\section{Publisher's Note}

Springer Nature remains neutral with regard to jurisdictional claims in published maps and institutional affiliations. 